\title{
Experience in Spain with local-national fora for better post-accident preparedness
}

\author{
E. Gallego ${ }^{1}$ and M. Montero ${ }^{2}$ \\ 1 Nuclear Engineering Department, Technical University of Madrid (UPM), C/ José Gutiérrez Abascal, 2, 28006 Madrid, Spain. \\ 2 Environmental Department, CIEMAT, Av. Complutense, 40, 28040 Madrid, Spain.
}

\begin{abstract}
In recent years, in the framework of the European Research projects EURANOS, NERIS-TP and more recently PREPARE, CIEMAT and UPM have been working together in close collaboration with the Nuclear Safety Council (CSN) of Spain to develop a coherent framework for post-accident rehabilitation by involving national, regional and local stakeholders. The framework was tested in preparedness exercises organized in 2007 and 2013. The aim is the development of appropriate protection strategies as part of the consequence management and the transition to recovery. Different issues were the focus of the exercises, such as management of contamination in water, inhabited areas and agricultural areas, rehabilitation of livelihood and production, and communication issues. The main lesson from the exercises is that forums are the key mechanism for successful interaction and feedback along the chain local regional - national levels. Using scenarios built on realistic assumptions is of great help. Decision support systems facilitate identifying the main challenges, functions to fulfil and management alternatives, in the search for the best management strategies.
\end{abstract}

Keywords: accident / nuclear / emergency preparedness / stakeholder involvement / post-accident recovery / Spain

\section{Introduction}

Experiences from past accidents such as Chernobyl or Fukushima have demonstrated the importance of a more decentralized management in order to address the implementation of measures that affect the daily lives of people and their properties. This is embodied in the need to engage more directly at regional and local levels, as well as with other social partners and affected populations in emergency preparedness, and especially in the recovery phase and post-emergency rehabilitation.

In recent years, in the framework of the European Research projects EURANOS ${ }^{1}$ (Raskob et al., 2010), NERIS-TP ${ }^{2}$ and more recently PREPARE ${ }^{3}$, CIEMAT and UPM have been working together in close interaction with the Nuclear Safety

\footnotetext{
1 EURANOS (2004-2009): European approach to nuclear and radiological emergency management and rehabilitation strategies. Funded under FP6-EURATOM-RADPROT, contract No. FI6R-CT2004-508843

2 NERIS-TP (2011-2014): Towards a self-sustaining European Technology Platform on Preparedness for Nuclear and Radiological Emergency Response and Recovery. Funded under FP7-EURATOMFISSION, GA 269718.

${ }^{3}$ PREPARE (2013-2016): Innovative integrated tools and platforms for radiological emergency preparedness and post-accident response in Europe. Funded under FP7-EURATOM-FISSION, GA 323287.
}

Council (CSN) of Spain to develop a coherent framework for post-accident rehabilitation by involving national, regional and local stakeholders. The framework was tested in preparedness exercises organized in 2007 and 2013. The aim is to identify and involve relevant stakeholders in emergency preparedness to improve the development and implementation of appropriate protection strategies as part of the consequence management and the transition to recovery.

The exercises, carried out as case studies, were focused on different issues: management of water and hydrological basin contamination; management in contaminated inhabited areas, with issues such as relocation, return for evacuees, decontamination/clean up, and radioactive waste generation and management; management of contaminated agricultural areas, including production issues, such as options to produce clean food, and management of disposal contaminated food; communication issues, etc.

A summary of each of these case studies is presented below.

\section{ECORINTE-EURANOS exercise in 2007 (Gallego et al., 2009, 2010)}

The first experience was a decision-making exercise regarding post-accident management of contaminated freshwater bodies and catchments in the long term. It was organized in 
the framework of the CSN Annual Exercises and Simulations Program 2007. This was the first time that the CSN organized an exercise on decision-making in case of contamination of large water bodies. It was also a unique opportunity to test in a fully realistic environment the capabilities of the MOIRA system (Monte et al., 2009) as a decision support tool, which was one of the demonstration activities included in the EURANOS Project. The exercise was led by UPM together with the CSN and CIEMAT.

The aim was to test and improve the ability to communicate and interact between different cooperating agencies involved in the decision-making process following accidental events of radioactive contamination of water bodies. In particular, a simulation of the contamination resulting from a severe accident leading to releases of ${ }^{137} \mathrm{Cs}$ and ${ }^{90} \mathrm{Sr}$ in the basin of the Tagus River was performed (i.e. contamination on the regional scale).

Although there was no legal requirement, it was recognized that these kinds of exercises are essential for better preparedness. The exercise featured the participation of the organizations responsible for emergency management and the affected services, as well as local and regional stakeholders plus several international observers. It was successful and provided several useful lessons and conclusions. It unveiled the need for a better interface and understanding between agencies and stakeholders. It also demonstrated that user-friendly wellstructured decision support systems may allow participants to have a greater awareness of respective competencies and capacities by aiding cross-actor interactions and thus contributing toward a better common understanding of the important issues.

\section{NERIS-2013/PENTA exercise in 2013}

NERIS-2013/PENTA was a coordination exercise on recovery and long-term management following a nuclear emergency caused by a severe accident with external consequences. It included the participation of the organizations responsible for emergency management at the national, regional and local levels and other selected stakeholders. Preparation for the exercise began in 2011, and it was finally organized in June 2013. It was based on the EURANOS/NERIS framework for postaccident preparedness (Dubreuil et al., 2010). The emphasis was concentrated on the engagement with local stakeholders. Much attention was dedicated to the post-accident situation of the Fukushima Daiichi NPP and the current management of contaminated territories around it, trying to recreate a similar post-accident situation in a Spanish scenario and to analyze the possible management of contaminated territories in the midand long term.

The exercise was headed by CIEMAT and UPM, with the support and collaboration of the CSN. Also, local support from the Sub-Delegation of the Government in the province was essential to achieve success in its development.

The final objective of the table-top exercise was to perform a complete analysis and discussion of the threats, sensitivity of the area, mitigating alternatives and their feasibility and effectiveness, as well as the involvement of local, regional and national actors in their effective implementation. The conclusions of the exercise helped to clarify the roles and responsibilities better at each level and to identify the need for improvement with regard to cooperation along the chain national $\Leftrightarrow$ regional $\Leftrightarrow$ municipality/local.

\section{CURIEX exercise in 2013}

CURIEX 2013 (Cáceres International Urgent Response Exercise) was a full-scale emergency drill in response to a nuclear accident in Almaraz NPP (Cáceres), aiming at testing the capabilities and resources of the Off-site Nuclear Emergency Plan (PENCA). An additional aim was to encourage exercises and collaboration between national and international support teams and the participation of citizens and the media in emergency exercise situations. The exercise was coordinated by the General Directorate of Civil Protection and Emergencies (DGPCE) of the Spanish Ministry of the Interior in cooperation with the Central Government Representative's Office (Subdelegación del Gobierno) in Cáceres, and the European Commission ${ }^{4}$.

The CSN, with the agreement of the DGPCE, engaged the NERIS-TP teams at UPM and CIEMAT in order to design the technical accident scenario for the third day, which was a tabletop exercise to discuss the problems of the post-accident transition phase to recovery. It was assumed that land contamination levels and their spatial distribution were already reasonably well characterized, including a direct release of contaminated water to the Tagus River after a few days. Two meetings were organized with a wide representation of national, regional and local administrations. In these preparatory meetings, methods and tools applicable to debate, analyze and decide the longterm rehabilitation phase were presented. There was an exchange of opinions looking to identify the main customization needs of the tools. UPM and CIEMAT developed a complete scenario for the transition phase to long-term management of the rehabilitation phase using JRODOS (Ievdin et al., 2010), ERMIN (Charnock, 2010), the EURANOS Handbooks (Nisbet et al., 2010) in Spanish and MOIRA (Monte et al., 2009). Emphasis was placed on the river-reservoir contamination, which could affect the Portuguese sections of the Tagus River. The table-top exercise took place in 5-6-7 November 2013 in Cáceres, and about 30 delegates of national, regional and local administrations were present, together with some stakeholders from a local university and public water supply company, as well as international stakeholders from Portugal (Ministry of the Environment, Territory and Energy).

\section{Methodology}

In the exercises described in Spain, a general methodology was followed, based on the EURANOS/NERIS framework for post-accident preparedness. Before starting, it is essential to have the support from the regulatory authorities as well as from the emergency planning authorities at national and local levels.

\footnotetext{
4 http://www.curiex.es/en/home
} 
Table-top exercises can be developed in order to perform a complete analysis and discussion of the threats, sensitivity of the areas, mitigating alternatives and their feasibility and effectiveness. The involvement of different actors in the effective implementation of mitigating actions should also be a main topic, looking to clarify the roles and responsibilities better at each level and to identify the need for improvement with regard to cooperation along the chain national $\Leftrightarrow$ regional $\Leftrightarrow$ municipality/local.

The methodology was applied in several phases. The first started by selecting the territories where the forum on emergency and post-emergency preparedness would be implemented. Then, preparatory meetings with the supporting authorities and national, regional and local authorities' representatives are essential to discuss and fix the objectives, show the available tools, and the way to develop the exercise.

Next, once the objectives of the exercise are clear, technical support organizations should develop a preliminary version of the scenarios to be analyzed by using the main computational and decision-aid tools available: JRODOS, ERMIN, MOIRA, the EURANOS Handbooks, etc. Feedback from the supporting authorities is needed, to be sure that the scenarios are targeted adequately to the objectives.

To help share understanding of the radiological situation, and the complexity of the emergency and postemergency situations, it would be very useful to organize workshops/seminars on past accident experiences, such as Chernobyl or Fukushima, to present and discuss precise cases and the lessons learnt. Also, the tools can be presented, and how they can help understand the accident scenarios can be shown. A final discussion of the workshop would allow making the fine-tuning of the calculations to finalize the scenarios, and identify the zones within vulnerable areas susceptible to intervention, as well as a selection of potential countermeasures analyzing their impacts.

To develop the exercises, it is important to include all relevant stakeholders: national, regional and local civil protection authorities and key staff members; nuclear or radiological safety regulatory authorities; representatives of the main logistic actors: emergency responders, and security and public order representatives from all levels (national, regional, local); health services; radioactive waste management organization; food and water control authorities and farming stakeholders; local authorities (mayors and key staff members); and other stakeholders and/or observers/advisors.

The choice of the topics to discuss is also a key factor for success. For each topic, the emphasis should be placed on the engagement with local stakeholders. In the exercises in Spain, in general, the topics discussed were centered along four main lines, generally with regard to the transition phase to recovery, under the assumption that an exhaustive radiological characterization must be available together with a continuing radiological survey (in the exercises, land contamination levels and their spatial distribution were taken from the output of the JRODOS system):

- Urban areas: organization of temporary housing and services for the temporarily relocated population. Conditions for the return of the evacuated population; decontamination strategies of the urban environment; criteria for assessment. Identification of those areas requiring a longer temporary relocation. Feasibility and impacts associated with decontamination of inhabited areas. Radiological control of areas and people during and after cleaning. Management of radioactive waste generated.

- Social aspects: recovery of disrupted social and economic activity after several months. Which mechanisms to implement by which actors to achieve a limited socio-economic impact. Financial resources and compensation mechanisms. Accommodation and services out of the relocatedcontaminated areas. Organization of transfer and return of population. Communication policies: transparency. The challenging return to normality and public perception.

- Agricultural areas: radiological control of food and drinking water during the emergency phase. Economic implications associated with market rejection of products, both for the impacted and surrounding areas. Organization of permanent surveillance systems. Management options in the affected areas, looking to international experience. Suitability of the available simulation tools for the region studied with local peculiarities (vineyards, fruit trees, rice, etc.). Monitoring for large food production systems. Adequate communication channels with the consumers.

- Basins and hydraulic systems and their use: importance of reliable predictions of the long-term evolution of the radioactivity in water and fish. Alternative drinking water supplies for periods up to a few months. Need to ban fish consumption for some years. Special impact evaluation needs for fish farms, rice cultivation, etc. Actors who should be aware of and implicated in the preparedness. In particular for rivers crossing borders: importance of transnational arrangements for monitoring radioactivity in the environment, including the rivers and reservoirs at both sides of the border.

\section{Conclusions and lessons learnt}

The recovery phase is not currently included in the legal framework for Emergency Plans in Spain. It is desirable that the general framework of plans for the recovery phase is preset as part and complement of the emergency preparedness, to ensure a coherent transition from emergency to rehabilitation. In this phase, the stakeholders that would be engaged have to be identified, and begin to get involved in and coordinate an organizational and functional structure.

Activities such as the exercises carried out and the working groups created will serve to initiate the debate between administrations and stakeholders potentially affected on how to address and move forward in the preparation for the phase of transition or departure from the urgent phase, and how to plan the activities in the recovery phase.

A main conclusion was the necessity to involve all affected stakeholders, not just public administrative bodies (at national, regional and local levels), or other public entities (like, for instance, the public waste management company), but all public and private civil groups should be engaged. The involvement of the civil stakeholders concerned (whether public or private) in the process of decision-making during the recovery phase 
is not an immediate or easy procedure. Therefore, the elaboration of the recovery plan must be transparent and participatory in order to reach viable and acceptable strategies for all the diverse interested sectors. This fact was acknowledged by all participants who showed a high interest in continuing these kinds of exercises in the future, as part of the regular emergency preparedness activities.

Perhaps the main lesson from the different exercises performed in Spain is that forums are the key mechanism for successful interaction and feedback along the chain of local - regional - national levels. When national authorities and agencies meet regional and local authorities and stakeholders, the need for a better interface and understanding is usually revealed. Mutual knowledge and awareness of the respective competencies and capacities is the first step to establish stronger interactions. Using scenarios built on realistic assumptions is of great help. Decision support systems can be used to facilitate identifying the main challenges, functions to fulfil and management alternatives, in the search for the best options. Through dialogue and joint analysis, it is possible to have a common understanding of the important issues and reach the necessary consensus on the most efficient way to implement them.

\section{References}

Charnock T.W. (2010) The European model for inhabited areas (ERMIN) - developing a description of the urban environment, Radioprotection 45, S55-S61.
Dubreuil G.H., Baudé S., Lochard J., Ollagnon H., Liland A. (2010) The EURANOS cooperative framework for preparedness and management strategies of the long-term consequences of a radiological event, Radioprotection 45, S199-S213.

Gallego E., Magán M., Cadierno J.P.G., Gil E., Monte L., Hofman D. (2009) Long-term management of contaminated freshwater bodies and catchments. Decision making exercise with the MOIRA system, Radioprotection 44 (5), 683-688.

Gallego E., Monte L., Hofman D. (2010) End-users' expectations and experiences with the decision support system MOIRA-PLUS, Radioprotection 45 (5), S251-S262.

Ievdin I., Trybushny D., Zheleznyak M., Raskob W. (2010) RODOS re-engineering: aims and implementation details, Radioprotection 45, S181-S189.

Monte L., Brittain J.E., Gallego E., Håkanson L., Hofman D., Jiménez A. (2009) MOIRA-PLUS: A decision support system for the management of complex fresh water ecosystems contaminated by radionuclides and heavy metals, Computers and Geosciences 35 (5), 880-896.

Nisbet A.F., Brown J., Howard B.J., Beresford N.A., Ollagnon H., Turcanu C., Camps J., Andersson K., Rantavaara A., Ikäheimonen T., Duranova T., Oughton D., Kirchner G., Papachristodoulou C., Ioannides K., Kwakman P. (2010) Decision aiding handbooks for managing contaminated food production systems, drinking water and inhabited areas in Europe, Radioprotection 45, S23-S37.

Raskob W., Gering F., Lochard J., Nisbet A., Starostova V., Tomic B. (2010) Overview and main achievements of the EURANOS project: European approach to nuclear and radiological emergency management and rehabilitation strategies, Radioprotection, 45, S9-S22.

Cite this article as: E. Gallego, M. Montero. Experience in Spain with local-national fora for better post-accident preparedness.

Radioprotection 51(HS1), S31-S34 (2016). 